\title{
CARACTERIZAÇÃO DE SISTEMAS DE INTEGRAÇÃO LAVOURA-PECUÁRIA-FLORESTA (ILPF) POR MEIO DE IMAGENS DE SATÉLITE.
}

\author{
Rodrigo Ratti Brolo*, Jansle Vieira Rocha, Aliny Aparecida dos Reis.
}

\section{Resumo}

Com o crescimento da população mundial, legislações mais rígidas sobre desmatamento e aumento da demanda por produção vegetal (grãos) e animal (carnes), tornou-se necessária intensificação do uso das terras agricultáveis. Os sistemas de integração lavoura-pecuária-floresta (ILPF) permitem o aumento da produção sem necessidade de expansão da área explorada e consequentes desmatamentos. Os sistemas ILPF tem sido adotados em algumas regiões no mundo e, dadas as suas condições climáticas, especialmente no Brasil. A dificuldade em se detectar e mapear essa dinâmica de uso da terra não permite quantificar essas áreas. Perfis de séries temporais de imagens de satélite tem potencial para tal mapeamento. Assim, o presente estudo tem como objetivo caracterizar sistemas de integração na Fazenda Santa Vergínia (Santa Rita do Pardo/ MS) por meio do uso de séries temporais de índices de vegetação do sensor MODIS, a bordo dos satélites Terra e Aqua. Os resultados indicam que é possível caracterizar sistemas ILPF por meio dessas séries temporais.

Palavras-chave: sensoriamento remoto, sistemas integrados de produção, séries temporais.

\section{Introdução}

Os sistemas de integração visam a produção vegetal, animal e florestal em uma mesma área, contribuindo para a sustentabilidade do sistema de produção, pois melhoram as condições microclimáticas (umidade do ar, redução da amplitude térmica e barreira de ventos), com impactos positivos na produção animal. Por consistirem em sistemas dinâmicos de uso da terra, o uso de sensoriamento remoto é fundamental para o seu monitoramento e mapeamento (ADAMI et al., 2012). O objetivo desse estudo consiste na identificação e caracterização de diferentes sistemas de integração presentes na Fazenda Santa Vergínia, por meio de séries temporais dos índices de vegetação NDVI (Normalized Difference Vegetation Index) e EVI (Enhanced Vegetation Index) do sensor MODIS.

\section{Resultados e Discussão}

Os perfis temporais de índices de vegetação (NDVI e EVI) foram obtidos no sistema SATVeg (ESQUERDO et al., 2011), a partir de imagens do sensor MODIS, a bordo das plataformas orbitais Terra e Aqua. As Figuras 1 (a) e 2 (a) mostram o perfil característico do NDVI de uma plantação de eucalipto. Já as Figuras 1 (b) e 2 (b) mostram o perfil temporal para uma área com integração Pecuária-Floresta e as Figuras 1 (c) e 2 (c) uma área somente com pastagem.

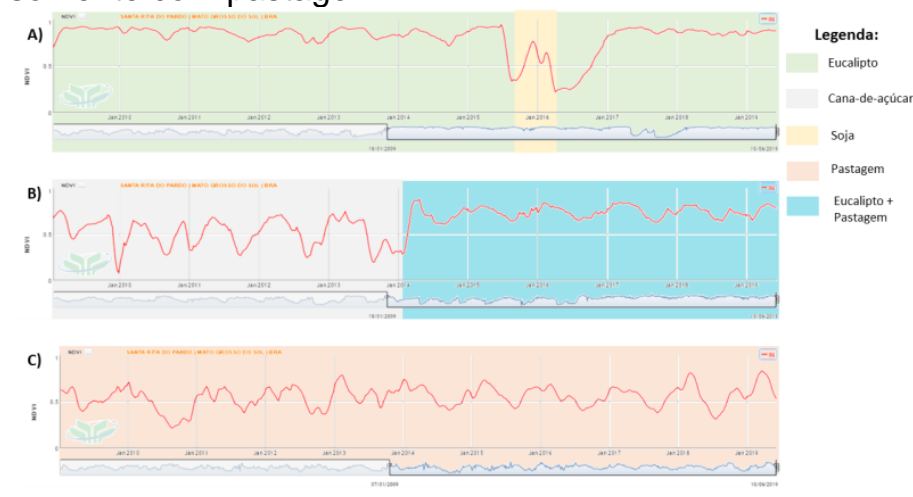

Figura 1. Perfis temporais do índice de vegetação NDVI para diferentes integrações na Fazenda Santa Vergínia.

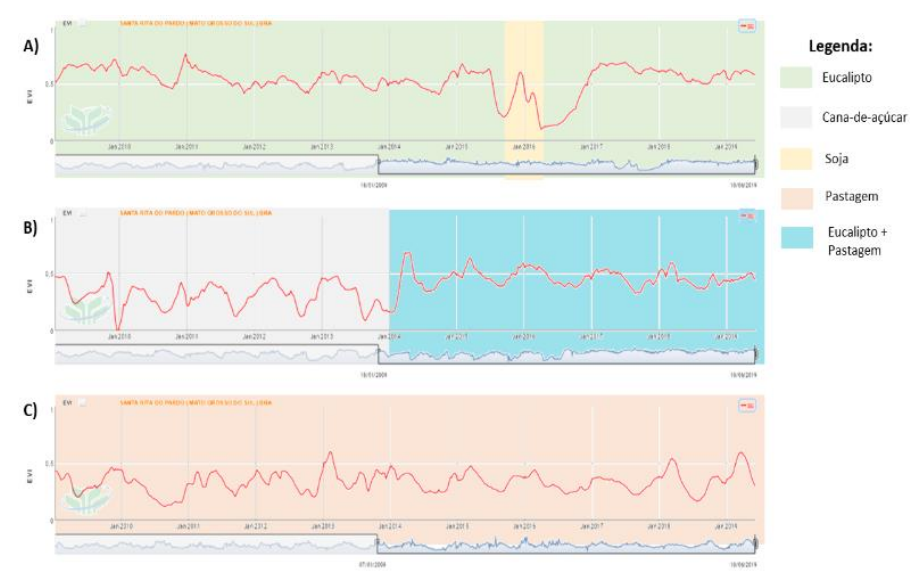

Figura 2. Perfis temporais do índice de vegetação EVI para diferentes integrações na Fazenda Santa Vergínia.

\section{Conclusões}

Os perfis temporais dos índices de vegetação (NDVI e EVI) do sensor MODIS permitiram a identificação dos diferentes sistemas de integração Lavoura-PecuáriaFloresta na Fazenda Santa Vergínia, demonstrando potencial para 0 desenvolvimento de classificadores digitais que possibilitarão o mapeamento de áreas semelhantes em larga escala.

\section{Agradecimentos}

Os autores agradecem ao CNPq pela concessão da bolsa de iniciação cientifica ao primeiro autor, e ao Sr. José Albino Zacarin, gerente da Fazenda Santa Vergínia pelos dados fornecidos.

ADAMI, M.; RUDORFF, B. F. T; FREITAS, R. M.; AGUIAR, D. A.; SUGAWARA, L. M.; MELLO, M. P. Remote sensing time series to evaluate direct land use change of recent expanded sugarcane crop in Brazil. Sustainability, v. 4, n. 4, p. 574-585, 2012.

ESQUERDO, J. C. D. M.; ANTUNES, J. F. G.; ANDRADE, J. C. Desenvolvimento do Banco de Produtos MODIS na Base Estadual Brasileira. In: XV Simpósio Brasileiro de Sensoriamento Remoto, 2011, Curitiba-PR. Anais... São José dos Campos: INPE, p. 7596-7602, 2011. 